\title{
Rolling Contact Fatigue Life of Steel Rollers Treated by Cavitation Peening and Shot Peening*
}

\author{
Masanori SEKI**, Hitoshi SOYAMA***, Yuji KOBAYASHI****, \\ Daisuke GOWA**** and Masahiro FUJII** \\ ${ }^{* *}$ Graduate School of Natural Science and Technology, Okayama University \\ 3-1-1, Tsushima-Naka, Kita-ku, Okayama 700-8530, Japan \\ E-mail: seki@mech.okayama-u.ac.jp \\ ***Department of Nanomechanics, Tohoku University \\ 6-6-01, Aramaki-Aoba, Aoba-ku, Sendai 980-8579, Japan \\ ${ }^{* * * *}$ New Product Development Center, Sintokogio, Ltd. \\ 3-1, Honohara, Toyokawa, Aichi 442-8505, Japan
}

\begin{abstract}
The purpose of this study is to investigate the influence of peening on the rolling contact fatigue (RCF) life of steel rollers. First, steel rollers were treated by three types of peenings to ensure the same surface roughness of peened rollers. One is the cavitation peening $(\mathrm{CP})$ used a cavitating jet in water with an injection pressure of $30 \mathrm{MPa}$, and the others are the fine particle peening (FPP) with a shot diameter of $0.1 \mathrm{~mm}$ and the normal shot peening (NSP) with a shot diameter of $0.3 \mathrm{~mm}$. The surface hardness and the surface compressive residual stress of the steel rollers were increased by all the peenings. In particular, they were most increased by the FPP. On the other hand, the work-hardened depth due to the CP and the NSP was larger than that due to the FPP. As a result of the RCF tests, the RCF lives of the steel rollers were improved by all the peenings, and they were most improved by the NSP. Judging from the $p_{\max }-N$ curves and the $\left[A\left(\sigma_{\mathrm{y}} / \sqrt{3} \mathrm{HV}\right)\right]_{\max }-N$ curves, the improvement in RCF lives due to the FPP depended heavily on the increase in surface hardness due to that, and the effects of the CP and the NSP on the RCF were equivalent under the same surface roughness and the same surface hardness. It follows from these that the surface treatment condition should be selected according to the rolling contact conditions and the failure modes of machine elements.
\end{abstract}

Key words: Rolling Contact Fatigue, Cavitation Peening, Shot Peening, Fine Particle Peening, Surface Roughness, Hardness, Residual Stress

\section{Introduction}

Shot peening (SP) is a surface treatment method widely used to improve the fatigue life of metallic components in the aerospace and automobile industries. In the SP, the material surface is impacted with a multitude of small hard shots projected at high velocity, and then the change in the mechanical properties on the shot-peened surface is caused. In particular, the SP below $0.2 \mathrm{~mm}$ shot diameter and $0.15 \mathrm{mmA}$ arc height is called fine particle peening (FPP). The FPP is reportedly effective for the control of surface topography in addition to the increase in fatigue strength ${ }^{(1)}$, and has already been put to practical use in the surface treatment method for machine elements. On the other hand, cavitation peening $(\mathrm{CP})$, which

*Received 14 Nov., 2011 (No. 11-0690) [DOI: 10.1299/jmmp.6.478]

Copyright $@ 2012$ by JSME 
does not require shots unlike SP, is a surface treatment method, and it can provide the increase in hardness and compressive residual stress near surface with less surface roughness change. Our previous study ${ }^{(2)}$ revealed that the rolling contact fatigue (RCF) life of cavitation-peened rollers increased with increasing processing time of the CP within 30 min. Therefore, in this study, the steel rollers were treated by the CP and the SP to ensure the same surface roughness of the peened steel rollers, and their RCF tests were performed in order to investigate the influence of the CP and the SP on the RCF life of the steel rollers.

\section{Test Specimens}

A test roller pair employed in the RCF tests consists of the slower test roller and the faster mating roller with $60 \mathrm{~mm}$ in diameter. Figure 1 shows the shapes and the dimensions of the test roller pair. The test rollers and the mating rollers were made of chromium molybdenum steel (JIS: SCM415). The heat treatment before quenching and tempering for the test rollers was carburizing, and that for the mating rollers was carbonitriding. These rollers were finish-ground after the heat treatment. Finally, their finish-ground circumferential surfaces were treated by the CP and the SP. Here, the Young's modulus and the Poisson's ratio of the rollers are $206 \mathrm{GPa}$ and 0.3 , respectively.

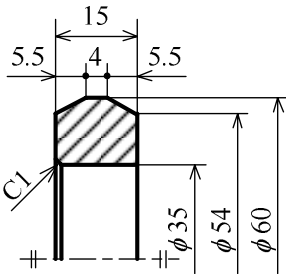

(a) Test roller

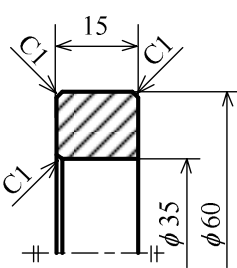

(b) Mating roller

Fig.1 Shapes and dimensions of test roller pair

Table 1 Cavitation peening condition for test roller pair

\begin{tabular}{|c|c|c|}
\hline Condition nam & & $\mathrm{CP}$ \\
\hline Nozzle type & & $\mathrm{C}$ \\
\hline Injection type & & Water \\
\hline Nozzle diameter & $\mathrm{mm}$ & 2 \\
\hline Injection pressure & $\mathrm{MPa}$ & 30 \\
\hline $\begin{array}{l}\text { Water pressure } \\
\text { in chamber }\end{array}$ & $\mathrm{MPa}$ & 0.42 \\
\hline Processing time & $\min$ & 5 \\
\hline Standoff distance & $\mathrm{mm}$ & 85 \\
\hline $\begin{array}{l}\text { Rotational speed } \\
\text { of roller }\end{array}$ & $\mathrm{rpm}$ & 20 \\
\hline
\end{tabular}

Table 2 Shot peening conditions for test roller pair

\begin{tabular}{|c|c|c|}
\hline Condition name & FPP & NSP \\
\hline Shot material & $\begin{array}{c}\text { Fe-based } \\
\text { amorphous }\end{array}$ & $\begin{array}{l}\text { Conditioned } \\
\text { cut wire }\end{array}$ \\
\hline Shot diameter & 0.1 & 0.3 \\
\hline Shot hardness & 900 & 600 \\
\hline Air pressure & 0.1 & 0.5 \\
\hline Peening time & \multicolumn{2}{|c|}{12} \\
\hline Arc height & 0.205 & 0.694 \\
\hline Coverage & \multicolumn{2}{|c|}{300} \\
\hline Shot distance & \multicolumn{2}{|c|}{150} \\
\hline $\begin{array}{l}\text { Rotational speed } \\
\text { of roller }\end{array}$ & \multicolumn{2}{|c|}{30} \\
\hline
\end{tabular}

Table 1 shows the $\mathrm{CP}$ condition for the rollers. $\mathrm{CP}^{(3)}$ is the peening by both the shock wave due to cavitation bubble collapse and the impact force due to micro jet. It uses a cavitating jet in water ${ }^{(4)}$ or a cavitating jet in air ${ }^{(5)}$. In this study, a cavitating jet in water, which is formed by injecting a high-speed water jet into a water-filled chamber, was used. Tap water was also employed to produce a high-speed water jet. The rollers were mounted in the chamber filled with tap water, and their rotational speed was $20 \mathrm{rpm}$ during the CP.

Surface roughness is one of the factors which influence the RCF life of machine elements, then the increase in surface roughness due to the peenings induces the decrease in the RCF life ${ }^{(6)}$. As described later, the arithmetic average roughness, that is surface roughness, of the cavitation-peened test roller was $0.27 \mu \mathrm{mRa}$. In order to investigate the influence of the CP and the SP on the RCF life of the steel rollers, two types of SP 
conditions shown in Table 2 were selected to ensure the same surface roughness as the cavitation-peened rollers. One was the FPP with a shot diameter of $0.1 \mathrm{~mm}$, and the other was the normal shot peening (NSP) with a shot diameter of $0.3 \mathrm{~mm}$. Here, the hardness of the shots employed in the NSP was $600 \mathrm{HV}$, softer than usual to reduce the increase in surface roughness due to the NSP, because the surface roughness is easily increased by the NSP. The SPs employed in this study were air SP, and the rollers were treated by these SPs, rotating them at a constant rotational speed of $30 \mathrm{rpm}$. The processing time of the $\mathrm{CP}$ and the peening time of the SPs were 5 min and $12 \mathrm{~s}$ for the roller, respectively.

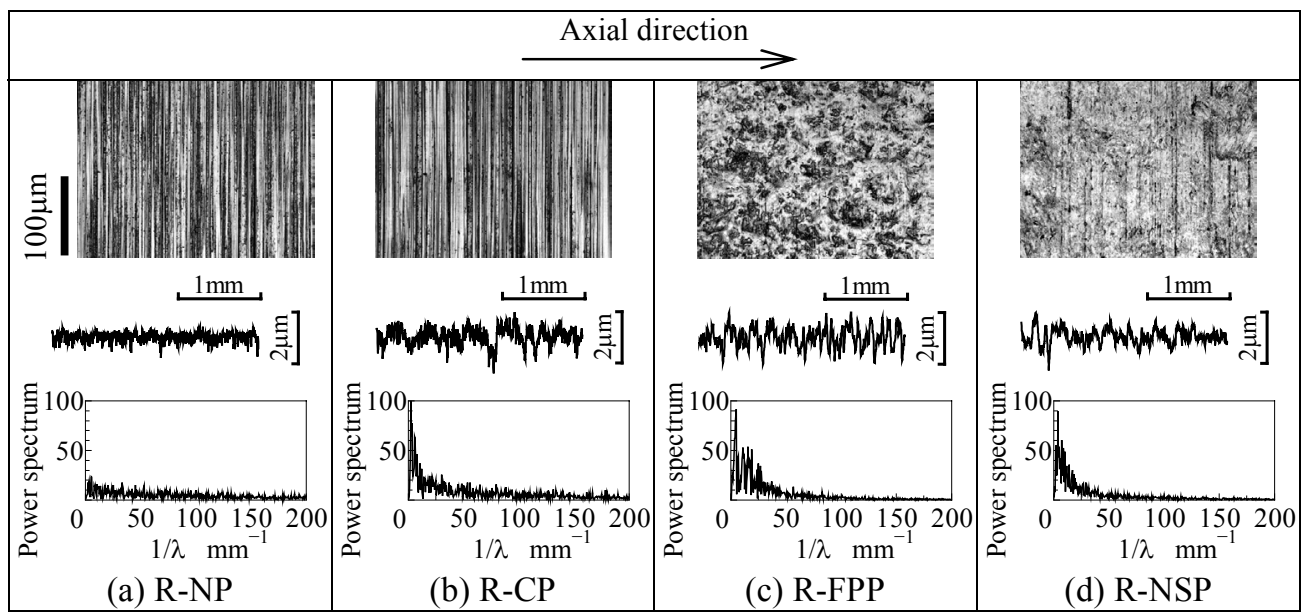

Fig.2 Surface photographs and roughness curves of test rollers

Figure 2 shows the surface photographs of the test rollers before the RCF tests. In the specimen shown in this figure, R placed before a hyphen represents the test roller, and R-NP represents the non-peened test roller. The surface photographs of the test rollers were taken by a scanning laser microscope. In this figure, the roughness curves of the test rollers and also the spectral analysis results of their roughness curves are shown. The roughness curves of the test rollers were measured on the circumferential surface along their axial direction using a surface roughness meter. It can be confirmed from this figure that the surface photograph of R-CP was similar to that of R-NP, and the grinding marks could be still observed on the roller surface of R-CP. In contrast, the grinding marks on the roller surfaces of R-FPP and R-NSP were disappeared by the FPP and the NSP, respectively. From the roughness curves of the test rollers, the amplitude of the roughness curves of the test rollers was increased by the peenings, and those of all the peened test rollers were almost the same. According to the spectral analysis results of the roughness curves, the power spectrum in the roughness curves of the peened test rollers was larger than that of R-NP in the range of $1 / \lambda$ smaller than $50 \mathrm{~mm}^{-1}$, that is, the range of the wavelength $\lambda$ longer than $0.02 \mathrm{~mm}$. For this reason, it can be said that the plastic deformation with large waviness was occurred by the peenings. Moreover, the power spectrum in the roughness curves of R-FPP and R-NSP were quite small in the range of the wavelength $\lambda$ shorter than $0.02 \mathrm{~mm}$. In this experimental range, the high-frequency component of the roughness curves was decreased by the SP. Even the same amplitude of the roughness curves of the peened test rollers, the roughness curve due to the $\mathrm{CP}$ was different from those due to the SP. This is one of the differences between the influences of the CP and the SP on steel surface.

Figure 3 shows the average hardness distributions of the test rollers. The Vickers hardness was measured with a micro hardness tester under a measuring load of $0.98 \mathrm{~N}$ for $30 \mathrm{~s}$. The average hardness distribution was obtained from five measured hardnesses at each depth below the circumferential surface of roller. As shown in Fig.3, the hardness near the circumferential surface of the test roller was increased by the peenings. In particular, the surface hardness of R-FPP was larger than those of the other test rollers. In terms of the 
work-hardened layer due to the peenings, the work-hardened depth due to the FPP was about $25 \mu \mathrm{m}$ below the roller surface, and those due to the CP and the NSP were about 75 $\mu \mathrm{m}$. The effective carburizing depths, where the hardness is $550 \mathrm{HV}$, were about $0.8 \mathrm{~mm}$ for the test rollers. The test roller and the mating roller peened under same condition were fatigue-tested as a test roller pair in this study. The average hardness distributions of the mating rollers indicated the similar tendency of those of the test rollers.

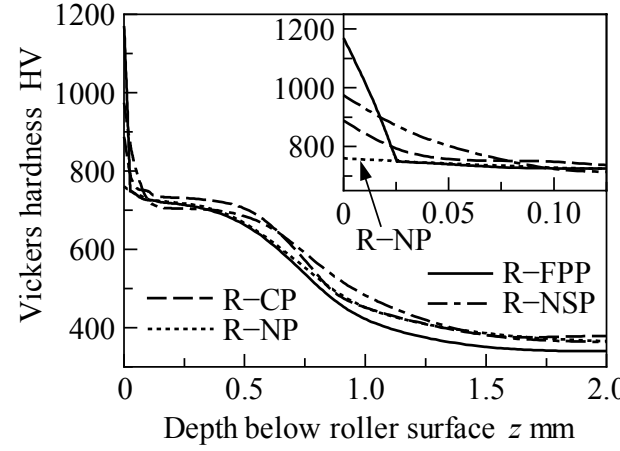

Fig.3 Hardness distributions of test rollers

Table 3 Surface properties of test rollers

\begin{tabular}{r|c|c|c|c}
\hline \multirow{2}{*}{ Specimen } & \multicolumn{4}{|c}{ Test roller } \\
\cline { 2 - 5 } & R-NP & R-CP & R-FPP & R-NSP \\
\hline$R \mathrm{a} \mu \mathrm{m}$ & 0.13 & 0.27 & 0.33 & 0.28 \\
\hline$R \mathrm{z} \mu \mathrm{m}$ & 1.28 & 2.48 & 2.09 & 2.21 \\
\hline $\mathrm{HV}$ & 760 & 888 & 1170 & 975 \\
\hline$\left(\sigma_{\mathrm{x}}\right)_{\mathrm{r}} \mathrm{MPa}$ & -370 & -724 & -1043 & -625 \\
\hline$\left(\sigma_{\mathrm{y}}\right)_{\mathrm{r}} \mathrm{MPa}$ & -117 & -639 & -1000 & -547 \\
\hline
\end{tabular}

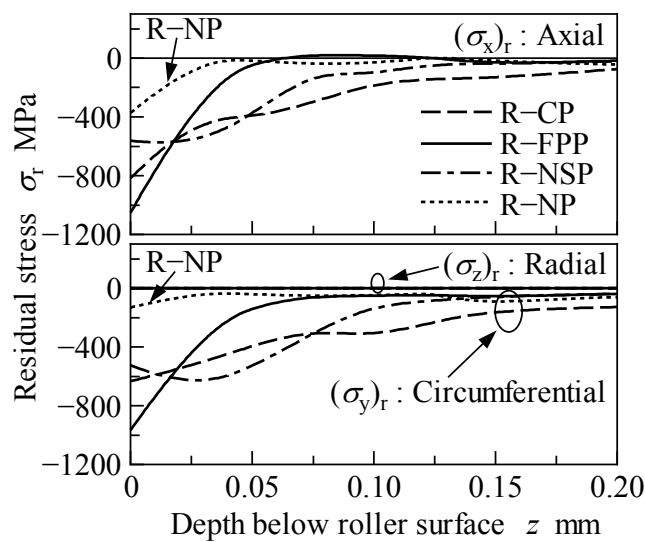

Fig.4 Residual stress distributions of test rollers

Table 4 Amount of retained austenite on test roller surfaces

\begin{tabular}{|c|c|c|c|}
\hline \multirow{2}{*}{\multicolumn{2}{|c|}{ Specimen }} & \multicolumn{2}{|c|}{ Amount of retained austenite } \\
\hline & & $\left(V_{\gamma}\right)_{\mathrm{x}} \%$ & $\left(V_{\gamma}\right)_{\mathrm{y}} \%$ \\
\hline \multirow{4}{*}{ Test roller } & R-NP & 46.02 & 45.10 \\
\hline & $\mathrm{R}-\mathrm{CP}$ & 40.47 & 35.94 \\
\hline & R-FPP & 29.64 & 28.79 \\
\hline & R-NSP & 32.66 & 37.10 \\
\hline
\end{tabular}

The residual stress distributions of the test rollers are shown in Fig.4. The residual stresses were measured according to the $2 \theta-\sin ^{2} \psi$ method (7) using CrK $\alpha$-ray as characteristic X-ray. For the stress analysis below the contact roller surface, an arbitrary point at the center of the roller surface was chosen as the origin, and the $x, y$ and $z$ coordinates were taken in the axial, the circumferential and the radial directions of the roller, respectively. The surface layer of the roller was removed by electrolytic polishing to measure the residual stress below the roller surface. The residual stresses $\left(\sigma_{\mathrm{x}}\right)_{\mathrm{r}}$ and $\left(\sigma_{\mathrm{y}}\right)_{\mathrm{r}}$ in the axial and the circumferential directions of the roller, shown in Fig.4, were determined by modifying the measured residual stresses by the elastic calculation ${ }^{(8)}$, since the measured stresses were influenced by the removal of the surface layer. The residual stress $\left(\sigma_{\mathrm{z}}\right)_{\mathrm{r}}$ in the radial direction of the roller was also determined by the elastic equations ${ }^{(8)}$. As can be seen in Fig. $4,\left(\sigma_{\mathrm{x}}\right)_{\mathrm{r}}$ and $\left(\sigma_{\mathrm{y}}\right)_{\mathrm{r}}$ of the peened test rollers were in compressive field in the surface layer. These compressive residual stresses were larger than those of R-NP. The compressive residual stress layer depths of R-CP and R-NSP were larger than that of R-FPP. Regarding the surface residual stress, the surface compressive residual stress of R-FPP was the largest among the test rollers, as in the case of the surface hardness. Here, $\left(\sigma_{\mathrm{z}}\right)_{\mathrm{r}}$ of all the test rollers were almost zero and constant with depth.

The surface roughness, the surface hardness and the surface residual stress of the test rollers are given in Table 3. Their surface roughness was obtained in the same manner as measuring the roughness curves shown in Fig.2, and the arithmetic average roughness $R \mathrm{a}$ and the maximum height roughness $R z{ }^{(9)}$ were used as roughness parameters in this study. Their surface hardness was determined from their hardness distributions shown in Fig.3. 
Their surface residual stress was obtained in the measurement of the residual stress distributions shown in Fig.4. The roughness parameters of the peened test rollers were almost the same as planned. As previously noted, the surface hardness and the surface compressive residual stress were most increased by the FPP in this experimental range. The largest increase in those due to the FPP is expected to be beneficial in improving the RFC life. The surface properties of the mating rollers also showed the same tendency of those of the test rollers.

Table 4 shows the amount of retained austenite on the circumferential surface of the test rollers. The amount of retained austenite was obtained in the same way as measuring the residual stress shown in Fig.4. In general, that is severely decreased by the plastic deformation induced phase transformation due to $\mathrm{SP}^{(10)}$. It can be seen from Table 4 that the amounts of retained austenite of the peened test rollers were smaller than that of R-NP, and that of R-FPP was the smallest among the test rollers. Thus, the plastic deformation amount due to the FPP was reflected in the amount of retained austenite, since the surface hardness and the surface compressive residual stress of R-FPP were the largest among the test rollers in this experimental range. On the contrary, the amount of retained austenite of R-CP was not greatly decreased by the plastic deformation due to the CP compared with the cases of R-FPP and R-NSP. It can be considered that the plastic deformation behavior due to the CP is different with that due to the FPP and the NSP, as in the case of the roughness curves of the test rollers shown in Fig.2.

\section{Experimental Procedure}

The RCF tests of the rollers were performed using a spring-loading type roller testing machine ${ }^{(11)}$. The load between the test roller and the mating roller was given by a compression spring. The maximum Hertzian stress $p_{\max }{ }^{(12)}$ was adopted as the standard of the loading between contact rollers. These RCF tests were performed under the sliding-rolling contact condition ${ }^{(11)}$ given in Table 5 . The test rollers were taken as the slower rollers, and the mating rollers were taken as the faster rollers. The lubricating oil employed in these tests was ATF. The properties of this lubricating oil are given in Table 6 . This lubricating oil was pressure supplied to the engaging side of the test roller pair from a nozzle. The flow rate of the supplied oil was about $1500 \mathrm{ml} / \mathrm{min}$ for the test roller pair. The oil temperature was adjusted to $313 \pm 4 \mathrm{~K}$.

Table 5 Rolling contact fatigue test condition of test roller pair

\begin{tabular}{l|c}
\hline Rotational speed of slower roller & $1432 \mathrm{rpm}$ \\
\hline Circumferential velocity of slower roller & $4.50 \mathrm{~m} / \mathrm{s}$ \\
\hline Rotational speed of faster roller & $1800 \mathrm{rpm}$ \\
\hline Circumferential velocity of faster roller & $5.65 \mathrm{~m} / \mathrm{s}$ \\
\hline Specific sliding of slower roller & $-25.7 \%$ \\
\hline Specific sliding of faster roller & $+20.4 \%$ \\
\hline Sliding velocity & $1.15 \mathrm{~m} / \mathrm{s}$ \\
\hline
\end{tabular}

Table 6 Properties of lubricating oil

\begin{tabular}{lr|c}
\hline & & ATF \\
\hline Specific gravity & $288 / 277 \mathrm{~K}$ & 0.8564 \\
\hline Flash point & $\mathrm{K}$ & 467 \\
\hline Kinematic viscosity & $313 \mathrm{~K}$ & 33.18 \\
\cline { 3 - 3 }$\times 10^{-6} \mathrm{~m}^{2} / \mathrm{s}$ & $373 \mathrm{~K}$ & 7.225 \\
\hline Viscosity index & & 191 \\
\hline
\end{tabular}

As described later, the RCF tests of the test rollers were performed under the maximum Hertzian stress of $2200 \mathrm{MPa}$ to $2600 \mathrm{MPa}$. The minimum oil film thickness by D.Dowson ${ }^{(13)}$, namely $h_{\text {min }}$ was in the range of $1.6 \mu \mathrm{m}$ to $1.7 \mu \mathrm{m}$ for the test roller pair. Then, the $D$ value defined by P.H.Dawson ${ }^{(14)}$ was above 1 for all the test roller pairs. In the calculation of the minimum oil film thickness and the $D$ value, the oil temperature between the contact roller surfaces was taken as $313 \mathrm{~K}$, which was the supplied oil temperature, in the RCF tests. In this study, the RCF life $N$ of the test rollers was defined as the total number of cycles when the roller testing machine was automatically stopped by the vibration increase 
due to the fatal surface failure.

\section{Experimental Results}

Figure 5 shows the photographs of the circumferential surface and the transverse section of the failed test roller. The failure mode of the test rollers employed in this study was pitting due to surface cracking, and the pitting suddenly occurred on the circumferential surface of the test roller in the RCF test. Specifically, the surface cracks of the test roller propagated below the roller surface in the rolling direction, and the fatal surface failure shown in Fig. 5 occurred due to the separation from the roller surface. In this study, the separation depth of the fatal surface failure of the test rollers was in the range of $0.5 \mathrm{~mm}$ to $1.0 \mathrm{~mm}$ below the roller surface.

Figure 6 shows the relationships between the maximum Hertzian stress $p_{\max }$ and the RCF lives $N$ of the test rollers obtained by the RCF tests. The arrow in this figure indicates that fatal surface failure did not occurred on the circumferential surface of the test roller, when the number of cycles of the test roller exceeded $2 \times 10^{7}$ cycles. The curves in this figure were obtained by the least square approximation of the symbols of the failed test rollers. These four approximate curves are almost parallel in this figure, and the approximate curve of R-NP lies to the left compared with those of the other test rollers. There is some variation in the RCF lives of the test rollers. However, it is obvious from this figure that the RCF lives of all the test rollers were improved by the peenings. By and large, those of R-NSP were the longest, followed by R-FPP, R-CP and R-NP.

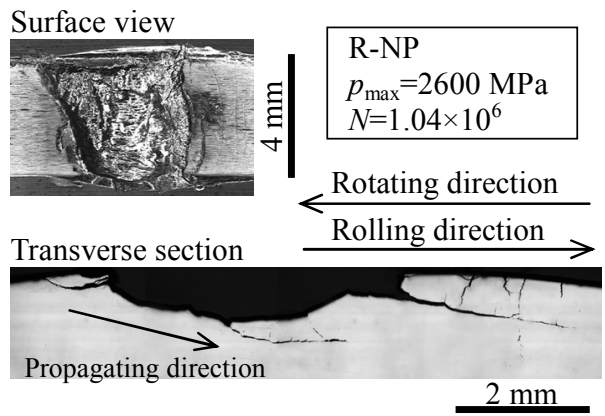

Fig.5 Observations of failed test roller

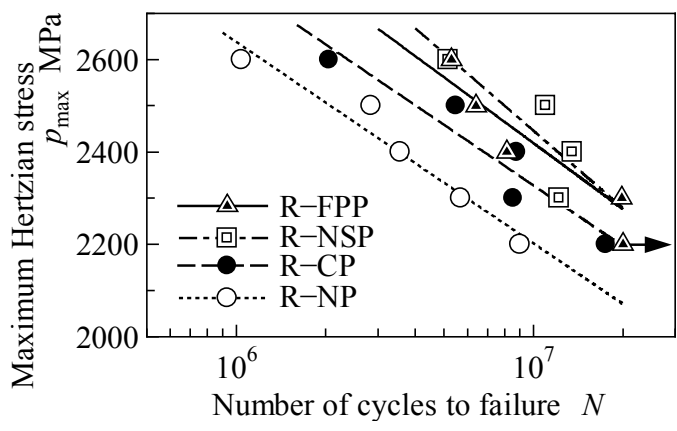

Fig.6 $p_{\max }-N$ curves of test rollers

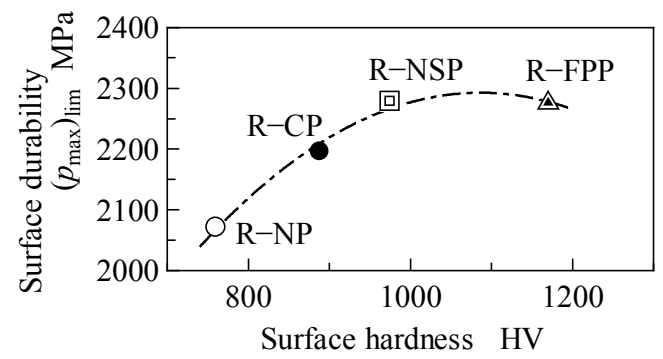

Fig.7 Relations between surface durability and surface hardness of test rollers

In this study, the fatigue limit in RCF of the test roller, that is, its surface durability $\left(p_{\max }\right)_{\lim }$ was defined as the maximum Hertzian stress $p_{\max }$ at $2 \times 10^{7}$ cycles. The relations between the surface durability $\left(p_{\max }\right)_{\lim }$ and the surface hardness of the test rollers are shown in Fig.7. From this figure, the surface durabilities of all the test rollers were also improved by the peenings. They have a tendency to increase with increasing the surface hardness of the test rollers. However, the surface durability of R-FPP with the largest surface hardness in this study was similar to that of R-NSP. The increase in surface durability due to the FPP did not keep pace with the increase in surface hardness due to the FPP, although the surface 
hardness and the surface compressive residual stress of R-FPP were larger than those of R-NSP.

\section{Evaluation of Rolling Contact Fatigue Life by Vickers Hardness and Normal Stress}

As previously noted, the failure mode of the test rollers was pitting due to surface cracking. Thus, tangential normal stress $\sigma_{\mathrm{y}}$ was considered because it became maximum on the surface ${ }^{(15)}$. In the calculation of this tangential normal stress on the contact surface, $x-y-z$ coordinate system was taken in the same direction as measuring the surface properties of the test rollers. Tangential normal stress $\sigma_{\mathrm{y}}$ on the circumferential surface of test roller was calculated under this coordinate system using the analytical method by J.O.Smith ${ }^{(16)}$.

As in the case of the carburized steel rollers employed in the past paper ${ }^{(15)}$, the maximum amplitude $\left[A\left(\sigma_{\mathrm{y}} / \sqrt{3} \mathrm{HV}\right)\right]_{\max }$ of the ratio of tangential normal stress $\sigma_{\mathrm{y}}$ to Vickers hardness HV was calculated by neglecting the effect of mean stress on fatigue and by assuming that the material strength of the test rollers is proportional to their hardness before the RCF tests. In the following paragraph, the RCF life and the surface durability of the test rollers were discussed by $\left[A\left(\sigma_{\mathrm{y}} / \sqrt{3} \mathrm{HV}\right)\right]_{\max }{ }^{(17)}$. For calculating this tangential normal stress $\sigma_{y}$, the surface residual stress of the test rollers shown in Table 3 was considered.

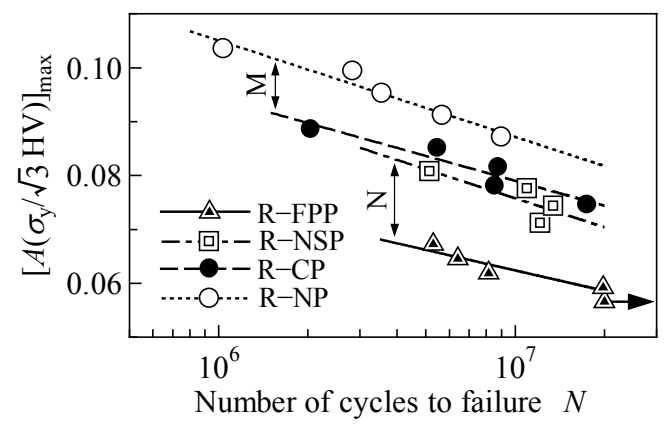

Fig.8 $\left[A\left(\sigma_{\mathrm{y}} / \sqrt{3} \mathrm{HV}\right)\right]_{\max }-N$ curves of test rollers

Figure 8 shows the relationships between the maximum amplitude $\left[A\left(\sigma_{\mathrm{y}} / \sqrt{3} \mathrm{HV}\right)\right]_{\max }$ and the RCF lives $N$ of the test rollers. This figure is the $\left[A\left(\sigma_{\mathrm{y}} / \sqrt{3} \mathrm{HV}\right)\right]_{\max }-N$ curves, where the maximum Herztian stress $p_{\max }$ in the ordinates of Fig.6 were exchanged for $\left[A\left(\sigma_{\mathrm{y}} / \sqrt{3} \mathrm{HV}\right)\right]_{\max }$. Here, the effect of surface hardness does not appear by using this evaluation method. Compared with Fig.6, the approximate curve of R-CP shown in Fig.8 is nearly coincident with that of R-NSP. This may be due to the fact that the work-hardened depth, the residual stress distribution and the surface roughness of R-CP were similar to those of R-NSP, respectively. Then, the approximate curves of R-CP and R-NSP lay beneath that of R-NP in Fig.8. It can be said from this that the RCF lives and the surface durabilities of R-CP and R-NSP were improved by the increase in surface hardness due to the peenings. Consequently, the effect of the CP on the RCF was equivalent to that of the NSP under the same surface roughness and the same surface hardness. The difference between $\left[A\left(\sigma_{\mathrm{y}} / \sqrt{3} \mathrm{HV}\right)\right]_{\max }$ of R-CP, R-NSP and R-NP, which is indicated by M shown in Fig.8, shows that the influence of the surface roughness mainly appears, since that of the surface hardness is eliminated, and the roughness parameters of R-CP and R-NSP were about twice as large as those of R-NP. The slight difference between $\left[A\left(\sigma_{\mathrm{y}} / \sqrt{3} \mathrm{HV}\right)\right]_{\max }$ of R-CP and R-NSP shows that the roughness curve due to the CP was different from that due to the NSP as shown in Fig.2.

On the other hand, the approximate curve of R-FPP lay far beneath those of the other test rollers. The difference between $\left[A\left(\sigma_{\mathrm{y}} / \sqrt{3} \mathrm{HV}\right)\right]_{\max }$ of R-CP, R-NSP and R-FPP, which is 
indicated by $\mathrm{N}$ shown in Fig.8, shows that surface roughness influence does not appear much, because the roughness parameters of R-FPP were almost the same as those of R-CP and R-NSP. In the case of R-FPP, while the surface hardness and the surface compressive residual stress of the test roller were extremely increased by the FPP, the work-hardened depth due to the FPP was smaller than those due to the CP and the NSP. Although the pitting, which is surface origin failure, occurred in the RCF tests, the separation depth of the fatal surface failure of the test rollers was in the range of $0.5 \mathrm{~mm}$ to $1.0 \mathrm{~mm}$ below the roller surface. It is necessary to be considered the surface crack occurrence as well as the crack propagation. Hence, the test rollers with extremely-different hardness distribution near the surface are difficult to be evaluated by means of the ratio of normal stress to surface hardness. However, it is clear that from Figs. 6 and 8 that the improvement in the RCF life and the surface durability due to the FPP depends heavily on the increase in surface hardness due to that.

Finally, as for the RCF of machine elements, the FPP is effective for surface failure prevention measure with a focus on the incidence of surface crack. In contrast, the $\mathrm{CP}$ and the NSP seem to be helpful in preventing the surface crack occurrence as well as the crack propagation, since the hardness and the compressive residual stress below the surface were increased by these peenings. In this study, the peened test rollers with same surface roughness were employed to ascertain the influence except for the surface roughness on the RCF life. In general, surface roughness is changed by peenings, and NSP is especially easy to induce the increase in surface roughness. In the case of the NSP over $0.2 \mathrm{~mm}$ shot diameter, using soft shots is effective for improvement of the RCF. This study revealed that the effect of the NSP on the RCF was equivalent to that of the CP under the same surface roughness and the same surface hardness, and was not equivalent to that of the FPP. Thus, the surface treatment condition should be selected according to the rolling contact conditions and the failure modes of machine elements.

\section{Conclusions}

This paper described the RCF test results of the steel rollers treated by the CP with an injection pressure of $30 \mathrm{MPa}$ and the SPs with shot diameters of $0.1 \mathrm{~mm}$ and $0.3 \mathrm{~mm}$. These three peening conditions were selected to ensure the same surface roughness of the peened test roller. The surface hardness and the surface compressive residual stress of the test rollers were increased by all the peenings, and they were most increased by the FPP with a shot diameter of $0.1 \mathrm{~mm}$. In contrast, the work-hardened depth due to the FPP was smaller than those of the CP and the NSP with a shot diameter of $0.3 \mathrm{~mm}$. The failure mode of the test rollers occurred in the RCF tests was pitting due to surface cracking. Using the ratio of normal stress to surface hardness, it was clear that the RCF life and the surface durability of the test rollers were improved by the increase in surface hardness due to the peenings. In particular, the improvement in those due to the FPP depended heavily on the increase in surface hardness due to that. On the other hand, the effects of the CP and the NSP on the RCF were equivalent under the same surface roughness and the same surface hardness, and was not equivalent to that of the FPP. In order to further improve the RCF, the FPP is required to give deeper work-hardened depth, and the NSP is required to use soft shots to reduce the increase in surface roughness due to that. Moreover, the $\mathrm{CP}$ is required to give larger surface hardness. Therefore, the surface treatment condition should be selected according to the rolling contact conditions and the failure modes of machine elements.

\section{Acknowledgments}

The authors would like to thank JX Nippon Oil \& Energy Corporation for the 
lubricating oil supply. The authors also thank Mr. Kazuhiko Hagiwara of Okayama University for his technical assistance. This research was supported financially in part by the General Research and Development Grant of Amada Foundation for Metal Work Technology to which the authors express their gratitude.

\section{References}

(1) Harada, Y., Fukaura, K. and Haga, S., Influence of microshot peening on surface layer characteristics of structural steel, Journal of Materials Processing Technology, Vol.191, No.1-3 (2007), pp.297-301.

(2) Seki, M., Soyama, H., Fujii, M. and Yoshida, A., Rolling Contact Fatigue Life of Cavitation-Peened Steel Gear, Tribology Online, Vol.3, No.2 (2008), pp.116-121.

(3) Soyama H., Park, J.D. and Saka, M., Use of Cavitating Jet for Introducing Compressive Residual Stress, Transactions of the ASME, Journal of Manufacturing Science and Engineering, Vol.122 (2000), pp.83-89.

(4) Odhiambo, D. and Soyama, H., Cavitation Shotless Peening for Improvement of Fatigue Strength of Carbonized Steel, International Journal of Fatigue, Vol.25 (2003), pp.1217-1222.

(5) Soyama, H., High-Speed Observation of a Cavitating Jet in Air, Transactions of the ASME, Journal of Fluids Engineering, Vol.127, No.6 (2005), pp.1095-1101.

(6) Girish, D.V., Mayuram, M.M. and Krishnamurthy, S., Influence of Shot Peening on the Surface Durability of Thermomechanically Treated En 24 Steel Spur Gears, Tribology International, Vol.30, No.12 (1997), pp.865-870.

(7) The Society of Materials Science, Standard Method for X-Ray Stress Measurement, (1982), p.4, The Society of Materials Science.

(8) Yonetani, S., On the Method of Measurement of Residual Stress in a Hollow Cylinder by X-Ray Method (in Japanese), Journal of the Society of Materials Science, Vol.18, No.9 (1944), pp.610-614.

(9) Bhushan, B. and Gupta, B.K., Handbook of Tribology: Materials, Coatings, and Surface Treatments, (1991), p.15.26, McGRAW-HILL.

(10) Dommarco, R.C., Kozaczek, K.J., Bastias, P.C., Hahn, G.T. and Rubin, C.A., Residual stresses and retained austenite evolution in SAE 52100 steel under non-ideal rolling contact loading, Wear, Vol.257 (2004), pp.1081-1088.

(11) Fujita, K., Yoshida, A., Yamamoto, T. and Yamada, T., The Surface Durability of the Case-hardened Nickel Chromium Steel and Its Optimum Case Depth, Bulletin of the JSME, Vol.20, No.140 (1977), pp.232-239.

(12) Johnson, K.L., Contact Mechanics, (1987), p.84, Cambridge University Press.

(13) Dowson D., Elastohydrodynamics, Proceedings of the Institution of Mechanical Engineers, Vol.182, Part. 3A (1967-1968) pp.151-167.

(14) Dawson, P.H., Further Experiments on the Effect of Metallic Contact on the Pitting of Lubricated Rolling Surfaces, Proceedings of the Institution of Mechanical Engineers, Vol.180, Part.3B (1965-1966), pp.95-100.

(15) Yoshida, A., Seki, M., Ohue, Y., Gotoda, Y. and Hayashi, D., Effect of Shot Peening on Pitting Strength of Case-Hardened Steel Roller, Proceedings of JSME Summer Annual Meeting, No.03-1 (2003), pp.19-20.

(16) Smith, J.O. and Liu, C.K., Stresses Due to Tangential and Normal Loads on an Elastic Solid With Application to Some Contact Stress Problems, Transactions of the ASME, Journal of Applied Mechanics, Vol.20, No.2 (1953), pp.157-166.

(17) Fujita, K. and Yoshida, A., Surface Durability of Steel Rollers, Bulletin of the JSME, Vol.23, No.178 (1980), pp.587-594. 